\title{
Research on Urban Smart Tourism Management System Based on System Management
}

\author{
Xu Zhu \\ Jilin Technology College of Electronic Information, Jilin, Jilin, 132021, China
}

Keywords: Informatization, Smart tourism, System management

\begin{abstract}
Tourism is developing very fast in China, and some cities have achieved good results in developing tourism, which has significantly promoted the development of local economy. Tourism informatization strongly supports the development of tourism, and has increasingly become the core competitiveness to win the advantage of global resource allocation. With the progress of information technology and the development of smart cities, smart tourism has become one of the hot spots and frontier issues in the research of tourism informationization theory and practice, and has been recognized by the academic circles as an important breakthrough to solve the bottlenecks and existing problems in the current tourism development. In the management of smart tourism, many information needs to be preserved and managed in order to analyze these data later. Smart tourism is not only a guiding strategy for tourism informatization construction, but also a deeper embodiment of the value of tourism informatization construction. This paper will analyze smart tourism based on system management, which will help to enrich and improve the theoretical research system of smart tourism, and promote the construction, development and innovation of smart tourism.
\end{abstract}

\section{Introduction}

In recent years, the state has attached great importance to the development of tourism in various regions and has continuously introduced new development measures. Tourism is an informationintensive industry, and tourism informatization plays an important supporting role in the development of the tourism industry, gradually gaining the advantage of global resource allocation in the form of core competitiveness [1]. With the advancement of information technology and the development of smart cities, especially the technological innovation and popularization of the Internet of Things, cloud computing, and mobile Internet, information exchange and sharing methods in the tourism industry, consumption patterns, operation supervision and management and other information transformations have become possible [2]. Smart tourism is a higher-level and more comprehensive guidance strategy for tourism informatization construction, and it is also a reflection of the deeper value of tourism informatization construction [3]. The tourism industry is highly dependent on information, and the effective transmission and circulation of information has become the source of its vitality. However, in the actual tourism process, problems such as the diversity and asymmetry of tourism information are very prominent. Tourism consumers, operators and management Everyone is eager for an accurate and efficient way of information communication [4]. With the strong support of the National Tourism Administration, information technology has become an important productive force for the development of tourism and an important supporting force to ensure the sustainable development of tourist attractions. Domestic tourism has been further developed, firmly establishing a dominant position in the industry.

The current overall development of the tourism industry in my country is faced with the relatively lagging development of tourism informatization, the widespread phenomenon of fragmentation of tourism resources, the low level of orderly management, and the imperfect functions of tourism platforms, which cannot fully meet the needs of the society and tourists [5]. Smart tourism is a new concept produced with the proposal of Smart Earth and Smart City, which mainly emphasizes the combination with the Internet and the Internet of Things to realize real-time perception of tourism resources and the environment and provide active and intelligent services [6]. 
The construction of a smart tourism system is of great significance for improving the image of my country's tourism industry and the level of service management. It is also conducive to promoting management innovation and introducing a new sustainable development model for the tourism service industry. In the context of the increasingly mature technology of enterprise management information systems, my country's urban tourism can promote and promote the development of national smart tourism through the construction and practice of smart tourism management systems [7]. This article will analyze smart tourism based on system management, which will help enrich and improve the theoretical research system of smart tourism, and promote the construction, development and innovation of smart tourism.

\section{The Significance of Urban Smart Tourism Service}

The occurrence and development of urban tourism has a long history. As the space carrier of tourism, cities are constantly adapting, adjusting and changing. This puts forward requirements for cities to adjust the structure and methods of their tourism supply system in a timely manner in the form of smart tourism. The tourism industry believes that smart tourism is a new form of tourism that faces the future and provides services to the public, enterprises and governments. Urban Smart Tourism is a comprehensive platform that provides information and intelligent application support for tourism services, management and marketing. The smart tourism management system provides a more efficient and intelligent information management platform for scenic area management departments, and provides tourists with a more convenient and flexible travel experience. The service software of each subsystem of the platform is published on different servers to ensure the normal operation of each service module [8]. Such a mechanism ensures that a single point of failure of the system will not affect the normal operation of other sub-modules, which increases safety and improves the availability and operating efficiency of the system. The diversification of service objects involved in urban smart tourism reflects the interactive relationship between tourism services, management and marketing. Therefore, the construction of an urban smart tourism system is a complex system project that takes into account multiple types of users, multi-function, big data, intelligence and integration.

While the country, provinces, cities, districts and counties as well as scenic spots are actively developing and constructing smart tourism systems, it is necessary to fully and comprehensively recognize the difficulties and risks that may be faced, and to put forward corresponding development strategies and evaluation standards. When faced with massive amounts of information and search results, users are often unable to make choices. The dispatch center can view the Beidou online list and the track information of the licensed tour guide on the map of the platform. Through the integration, research, tracking and analysis of tourism information, the marketing hot spots and tourists' hobbies can be discovered in time. The recommendation system can help users find useful information for themselves, and can also recommend information to users who may be interested in it. The business logic layer implements specific business logic in reality, and this layer needs to be divided separately. The data service layer is used for data exchange with the database during the system development process, and it provides services to the business logic layer. The recommendation system engine finds and ranks personalized recommendation results that meet the needs of users based on user models and various contextual information, such as basic data such as current weather and traffic conditions, and recommends them to users.

\section{Smart Tourism Management System}

\subsection{Basic Principles of System Construction}

In the urban smart tourism system, smart service, management and marketing systems interact with each other, so information integration and sharing of all application systems should be realized at the same time. In the application category, there are different service levels from cities, scenic spots to scenic spots. There are significant differences in the application of tourism informatization 
and smart tourism at different levels. Because of the different service objects and functions, urban smart tourism consists of a series of infrastructure and application systems. Because its construction is an inter-departmental and long-term task, each application system should be relatively independent and can be built separately and operated flexibly. The fundamental purpose of the intelligent tourism management system is to integrate related information such as tourist attractions, travel agencies, tour guides and other tourism information by relying on the portability and portability of mobile phones, and finally build a tourism-based portal [9]. There are many travel agencies and the prices are uneven, which makes it difficult for tourists to choose travel agencies. There is a lack of professional tourist guidance services and formed products suitable for tourists' peer-to-peer services, such as scenic spot commentary and scenic spot guide. By downloading the application of scenic spots, you can also get the electronic tour guide service, and get the exclusive tour guide's explanation service in real time when approaching the target. The system aims to calculate the location of tourists in the scenic spot, predict how long it will take to reach the next scenic spot, and assist the scenic spot staff to guide tourists.

\subsection{Composition of Urban Smart Tourism Application System}

Architecture design is the main work in the system design stage. Before designing the system architecture, we must have a comprehensive understanding of the application background, functional requirements, performance requirements and practical application environment of the system. In the system, scenic spots, road areas and fork roads are divided into different areas. Specify the direction of road data, and save the map zoning information and road network distance information. Then judge the location area according to the latest location data. City-level smart tourism application system is divided into service, management and marketing, including city smart tourism cloud service center and public service platform, integrated management platform and public marketing platform supported by it. The Web server is responsible for loading Baidu's map resources and displaying the data in the database on the map, and managers can query the information of people on the map. The database is responsible for recording the basic information and track information of personnel obtained through Beidou tour guide card. The geographic data acquisition architecture is shown in Figure 1.

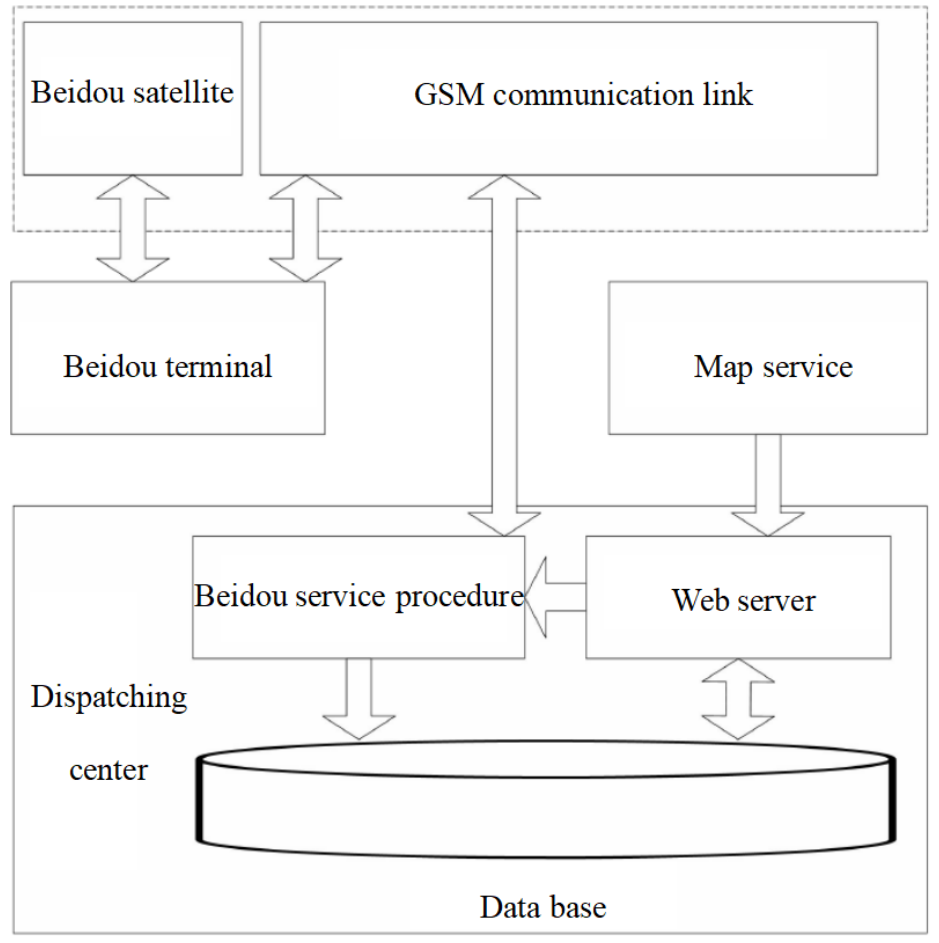

Fig.1 Geographic Data Collection Architecture

Tourism public information service is a win-win service mode, which not only helps to establish a good connection between tourists and tourist destinations, but also greatly benefits the 
development of tourism. Tourism companies or local tourism departments complete information transmission through these ways, so that more potential customers can be tapped. After completing a journey, tourists can summarize and analyze the information provided, which can effectively enhance tourists' recognition of tourist spots and further promote the improvement of service level and quality. The traffic solution based on Internet architecture is shown in Figure 2.

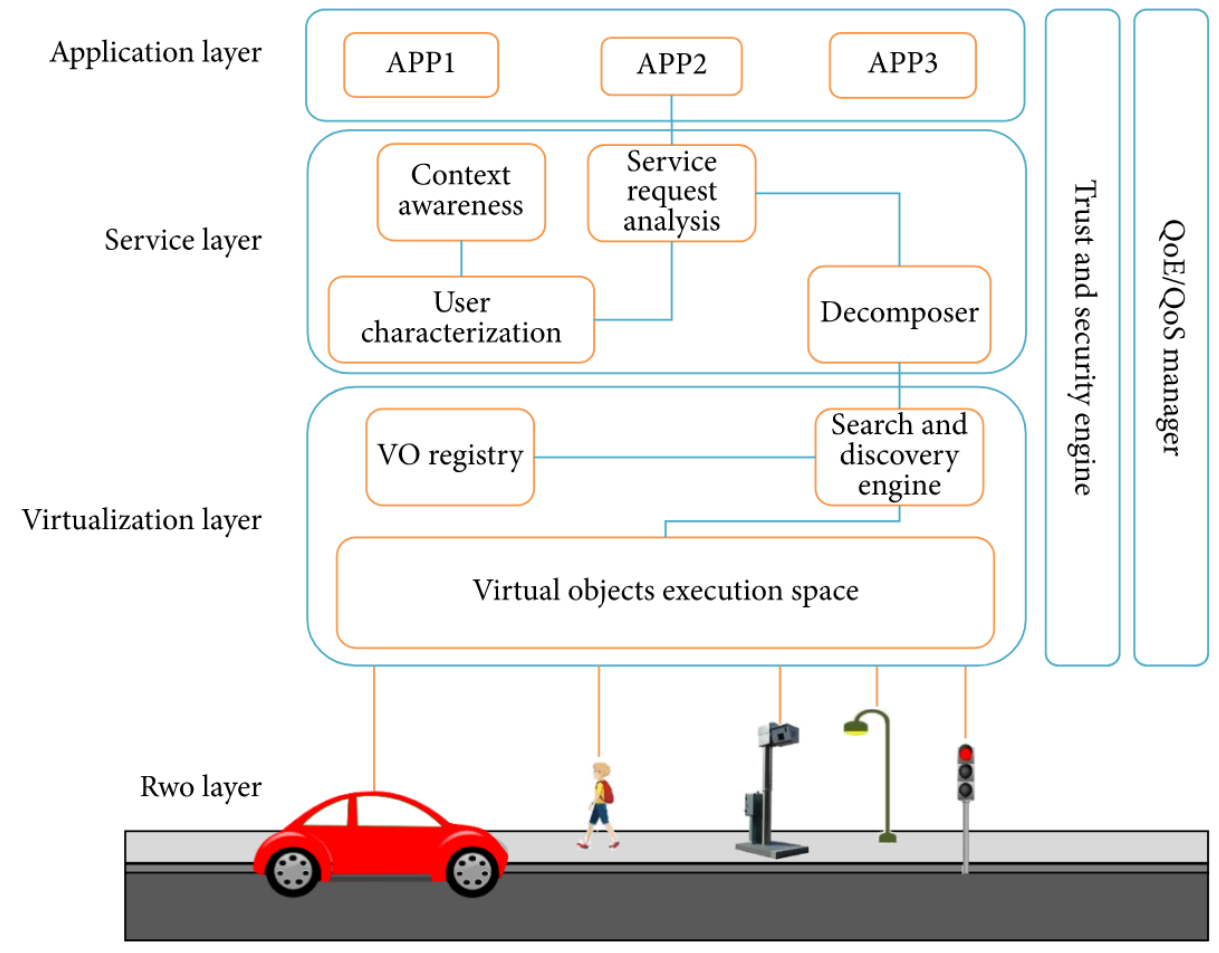

Fig.2 Traffic Solutions Based on Internet Architecture

Different application systems are based on a certain spatial scope, and smart tourism should be based on geographical space, integrating various tourism thematic elements and professional applications. As an integrated information service provider, communication companies provide intelligent tourism platforms and related information solutions for all links of the tourism industry chain. Travel agencies make full use of information and intelligent tourism service management platform. Provide the public with complete, detailed and reliable overall information of the journey, including route and guide information. Information is transferred between different levels to form a unified integrated system. In this system, the cloud service center, as the basic support, provides services for receiving, organizing, processing, storing, distributing and sharing data of tourists, tourism resources and tourism environment.

\section{Conclusions}

With the continuous improvement of living standards of Chinese residents, people put more energy into tourism. As a new tourism operation mode, intelligent tourism provides high-quality tourism services to tourists through intelligent management, intelligent service and intelligent experience with the help of various technical means such as the Internet, Internet of Things and cloud computing, and creates a win-win situation in which tourists are satisfied and tourism is profitable. Architecture design is the main work in the system design stage. Before designing the system architecture, we must have a comprehensive understanding of the application background, functional requirements, performance requirements and practical application environment of the system. Smart cities are generally promoted by local governments, and have perfect solutions and corresponding capital budgets in infrastructure construction. Smart tourism should make full use of the achievements of smart city construction and avoid duplication of construction. The construction of urban smart tourism system is a complex systematic project, which requires the integration and 
sharing of massive tourism information. Smart tourism management system should be an open system, which will be adjusted with the progress of science and technology and the development of society. Therefore, building a comprehensive, mature and open intelligent tourism management system still needs to be perfected through continuous practice and innovation.

\section{References}

[1] Xu Feng, Li Shuishai, Qi Xueqin. Reconstruction of tourism system model under the background of big data[J]. Tourism Science, 2016(1): 48-59.

[2] Li Guozhong. The application of artificial intelligence technology in smart tourism[J]. Automation and Instrumentation, 2017, (012):225-227.

[3] Huang Song, Li Yanlin, Dai Pingjuan. Evaluation of the tourism competitiveness of smart tourism cities[J]. Acta Geographica Sinica, 2017, 72(002):242-255.

[4] Zhou Bo, Zhou Lingqiang. Research on the business model of smart tourism abroad and its enlightenment to China [J]. Tourism Tribune, 2016, 31(006): 8-9.

[5] Jia Hongyan. Research on Public Information Service Strategy under the Background of Smart Tourism [J]. Information Science, 2015, 033(007):145-149.

[6] Ma Lei. Self-service travel system based on intelligent solutions [J]. Computer System Applications, 2017, 026(003): 57-62.

[7] Yu Ping, Zhu Wei, Gao Jiangjiang. The construction of tourism laboratory based on the "smart scenic spot” model [J]. Experimental Technology and Management, 2016, 033(007):237-240.

[8] Liang Bing, Wei Haiyang, Bai Yulong, et al. Research on intelligent management of traditional residential settlements and mobile tourism self-service system [J]. Remote Sensing for Land and Resources, 2015, 27(4): 188-193.

[9] Li Jun, Wang Hefei, Wei Lingyan. Research on Tourism Efficiency Evaluation of Smart Tourism Cities Based on DEA-Malmquist Method [J]. Mathematics in Practice and Knowledge, 2017, 47(011):299-306.

[10] Wang Sailan. The dissemination dilemma of cultural tourism resources under the background of smart tourism [J]. Tourism Tribune, 2019, 034(008):5-6.

[11] Liao Weijun, He Youshi. Research on the collaborative development mechanism of smart tourism service supply chain based on the global perspective [J]. Economic Research Reference, 2017, (025): 72-80.

[12] Zhang Jiantao, Wang Yang, Liu Ligang. Construction of smart tourism application model system under the background of big data [J]. Enterprise Economics, 2017, (005): 116-123. 